\title{
Efektivitas Terapi Relaksasi Benson untuk Meningkatkan Kualitas Hidup Lansia: Telaah Literatur
}

\author{
Dewati Wahyu Indah Sari ${ }^{*}$, Farah Zhafirah Syarafina ${ }^{1}$, Kristina Ayuningtias ${ }^{1}$, Nidia \\ Ainun $^{1}$, Putri Balgis Setianingrum¹, Shabrina Febriyanti ${ }^{1}$, Anung Ahadi Pradana ${ }^{2}$
}

1) Program Studi S1 Keperawatan STIKes Mitra Keluarga, Bekasi, Jawa Barat, Indonesia

2) Departemen Keperawatan Komunitas, Program Studi S1 Keperawatan STIKes Mitra Keluarga, Bekasi, Jawa Barat, Indonesia

*Corresponding author: dewatiwhy19@gmail.com

\begin{abstract}
Background: Elderly is someone who is more than 60 years old. Every elderly will experience a decrease in body function, in health and in quality of life. Benson relaxation therapy is a combination of deep breath relaxation and belief systems. Purpose: To determine the effectiveness of Benson's relaxation therapy on the quality of life of the elderly. Methods: The method in this study uses the Literature Review method taken from e-resources Google Scholar, Science Direct and Pubmed. The keywords used are "benson relaxation technique", "elderly" "benson relaxation therapy", "elderly" with the inclusion criteria of Benson therapy articles for the elderly using the randomized controlled trial (RCT) methodology, Indonesian and English articles published in the range 2018-2021 and the criteria exclusions are articles that do not use Benson therapy for the elderly, articles with a Review methodology or not RCTs and articles published before 2018. Results: Based on the search for articles according to inclusion and exclusion criteria, 10 articles were found which found that the Benson relaxation technique was effective for dealing with sleep disorders, anxiety, high blood pressure and high blood sugar in the elderly with an intervention time of 10-30 minutes a day. Conclusion: Based on the review of the 10 articles, it was stated that Benson relaxation therapy is effective for reducing sleep difficulties, anxiety, blood pressure, blood sugar, stress, and anxiety depression of sleep quality in hemodialysis patients in the elderly. This Benson relaxation technique is also effective for 10-15 minutes a day. For further researchers, the results of this study can be used as reference material to deepen further research, such as looking for more accurate and specific sources. And the knowledge can be upgraded, especially Benson therapy which is a non-pharmacological therapy so that it can help to overcome many problems of the elderly.
\end{abstract}

Keywords: effectiveness of benson therapy in the elderly, elderly, benson therapy

\begin{abstract}
ABSTRAK
Latar belakang: Lanjut usia merupakan seseorang yang telah berusia lebih dari 60 tahun. Setiap lansia akan mengalami penurunan fungsi tubuh dan penurunan kesehatan serta penurunan kualitas hidup. Terapi relaksasi benson merupakan gabungan dari relaksasi nafas dalam, pikiran dan sistem keyakinan. Tujuan: Untuk mengetahui efektivitas terapi relaksasi benson pada kualitas hidup lansia. Metode: Metode dalam penelitian ini menggunakan metode Review Literature yang diambil dari e-resources Google Scholar, Science Direct dan Pubmed. Kata kunci yang digunakan "benson relaxation technique", "elderly" "terapi relaksasi benson", "lansia" dengan kriteria inklusi artikel terapi benson terhadap lansia yang menggunakan metodologi randomized controlled trial (RCT), artikel bahasa indonesia dan inggris, terbit di
\end{abstract}


rentang tahun 2018 - 2021 serta kriteria eksklusi yaitu artikel bukan menggunakan terapi benson terhadap lansia, artikel dengan metodologi Review atau bukan RCT dan artikel terbit sebelum tahun 2018. Hasil: Berdasarkan pencarian artikel sesuai kriteria inklusi dan eksklusi didapatkan 10 artikel yang ditemukan bahwa teknik relaksasi benson efektif untuk mengatasi masalah gangguan tidur, kecemasan, darah tinggi dan gula darah tinggi pada lansia dengan waktu intervensi selama 10-30 menit dalam sehari. Simpulan: Berdasarkan telaah review 10 artikel tersebut menyatakan bahwa Terapi relaksasi benson efektif untuk menurunkan kesulitan tidur, kecemasan, tekanan darah, gula darah, stres, dan cemas depresi kualitas tidur pada pasien hemodialisa pada lansia. Teknik relaksasi benson ini juga efektif dilakukan selama $10-30$ menit dalam sehari. Bagi peneliti selanjutnya, hasil penelitian ini dapat digunakan sebagai bahan referensi untuk memperdalam penelitian berikutnya, seperti mencari sumber yang lebih banyak, akurat dan spesifik. Ilmu tersebut mampu diupgrade khususnya terapi benson yang merupakan terapi nonfarmakologi sehingga dapat membantu guna mengatasi banyak permasalahan lansia.

Kata kunci: efektivitas terapi benson pada lansia, lansia, terapi benson

\section{PENDAHULUAN}

Berdasarkan UU No.13 RI tahun 1998 Lanjut Usia (Lansia) adalah seseorang yang telah mencapai usia 60 tahun ke atas (1). Berdasarkan data Kemenkes pada tahun 2016 persentase lansia di Indonesia telah mencapai $9,03 \%$ dari keseluruhan penduduk (2). Penduduk lansia jumlahnya diprediksi pada tahun 2020 mencapai 27,08 juta, sedangkan pada tahun 2025 terdapat 33,69 juta, tahun 2030 ada 40,95 juta dan tahun 2035 mencapai hingga 48,19 juta. Semakin tingginya angka lansia menunjukkan bahwa semakin tingginya masalah kesehatan yang akan terjadi karena proses alamiah penuaan. Lansia pasti akan mengalami penuaan, proses penuaan adalah hal yang wajar bagi manusia. Proses penuaan dapat dilihat dari 3 perspektif, yaitu usia biologis yang berhubungan dengan fungsi organ, psikologis yang berhubungan dengan perilaku adaptasi, serta sosial yang berhubungan dengan peran perilaku sesuai usia manusia (3). Semakin bertambahnya usia semakin berkurangnya fungsi-fungsi biologis, psikologis dan sosial.
Pada penurun fungsi biologis dapat dilihat pada perubahan kondisi tingkat struktural sel atau organ tubuh, termasuk di dalamnya yang dipengaruhi oleh proses penyakit. Perubahan sel menyebabkan penurunan metabolisme tubuh dapat membuat jaringan tubuh lemah dan sakit serta terjadi penurunan fungsi organ-organ tubuh. Selain penurunan fungsi biologis adapula penurunan psikologis dan sosial, seperti menarik diri dari kehidupan sosial, hidup dengan penuh keputusasaan seperti takut mati, penyesalan diri, merasakan kesepian dan merasa terlambat untuk memperbaiki diri (4).

Penurunan fungsi tubuh secara biologis, psikologis dan sosial tersebut mengakibatkan adanya masalah kesehatan dan kesulitan memenuhi kebutuhan dasar bagi lansia. Salah satunya adalah permasalahan insomnia yang dialami oleh banyak lansia, di Indonesia prevalensi insomnia pada usia > 60 tahun ditemukan sebanyak 7\% kasus, kemudian ditemukan juga sebanyak 22\% lansia mengalami depresi yang merupakan beban penyakit nomor 3 di seluruh dunia (5). Selain itu, terjadi peningkatan Penyakit Tidak 
Menular (PTM) pada lansia, berdasarkan data Riskesdas pada tahun 2016 prevalensi Hipertensi pada usia 55-64 tahun 20,7\%, pada usia 65-74 tahun $26,7 \%$ dan lebih dari 75 tahun 27,9\% adapun Diabetes Mellitus pada usia 55-64 tahun 5,5\%, usia 65-74 tahun 4,8\% dan lebih dari 75 tahun sebanyak 3,5\% (6). Data terbaru menunjukkan penurunan pada prevalensi Hipertensi dengan usia 55-64 tahun 18,3\%, pada usia $65-74$ tahun $23,31 \%$ dan lebih dari 75 tahun $24,04 \%$ adapun pada Diabetes Mellitus terjadi peningkatan dengan usia 55-64 tahun 6,29\%, usia 65-74 tahun 6,03\% dan lebih dari 75 tahun sebanyak 3,32\%.

Masalah yang dialami lansia dapat diatasi dengan terapi farmakologi maupun nonfarmakologi. Salah satu terapi nonfarmakologi adalah terapi Relaksasi Benson. Relaksasi benson merupakan gabungan relaksasi antara teknik relaksasi napas dalam, pikiran dan sistem keyakinan seseorang (berupa ungkapan yang difokuskan pada nama-nama Tuhan atau kata yang memiliki makna ketenangan bagi individu itu sendiri) diucapkan berulang dengan ritme teratur disertai sikap pasrah. Relaksasi benson ini suatu metode nonfarmakologis yang melibatkan kemampuan pikiran yang dapat menyembuhkan sistem tubuh. Relaksasi benson dapat mengurangi respon yang berlebihan terkait respon fight or flight dan membuat individu menjadi merasa rileks (7-9). Teknik Relaksasi benson dapat dilakukan dengan cara; duduk dalam posisi yang nyaman, menutup mata, melemaskan semua otot secara mendalam, mulai dari kaki hingga ke wajah, dan bernapas melalui hidung sambil merasakan hembusan napasnya, Teknik ini dilakukan berulang selama 20 menit (10). Kemudian berdiam duduk selama beberapa menit dan membuka mata secara perlahan. Meskipun
Relaksasi Benson dirancang untuk mengatasi kecemasan, penulis menemukan pada beberapa penelitian didapatkan manfaat lainnya. Berdasarkan paparan tersebut, kami ingin melihat adakah efektivitas dari terapi relaksasi benson pada lansia.

Penulisan telaah artikel sederhana ini dilakukan dengan penelusuran database jurnal yang dipublikasikan secara online dengan menggunakan Google Scholar, Science Direct dan Pubmed. Kriteria pengambilan artikel adalah yang sesuai kata kunci "benson relaxation technique", "elderly" "terapi relaksasi benson" "lansia" dan dengan kriteria inklusi yang ditetapkan adalah artikel dengan topik efektifitas terapi benson terhadap lansia yang menggunakan metodologi randomized controlled trial (RCT), artikel bahasa Indonesia dan Inggris, terbit di rentang tahun 2018 - 2021 serta kriteria eksklusi yang ditetapkan adalah artikel yang bukan menggunakan terapi benson terhadap lansia, artikel yang menggunakan metodologi Review atau bukan randomized controlled trial (RCT) dan artikel yang terbit sebelum tahun 2018. Jumlah artikel akhir didapatkan hasil sebanyak 10 artikel yang sesuai.

\section{TINJAUAN LITERATUR}

Berdasarkan 10 artikel yang telah ditelaah, didapatkan hasil bahwa pasien lansia yang melakukan teknik relaksasi benson ini membantu mereka dalam membantu menurunkan stress, gangguan tidur, menurunkan cemas, mengurangi cemas pada lansia yang menjalankan hemodialisa, menurunkan gula darah dan tekanan darah pada lansia hipertensi. Pasien mengatakan bahwa ada pengaruh dari teknik relaksasi benson terhadap gangguan kecemasan, stress, kualitas tidur dan dapat menurunkan 
tekanan darah dan kadar gula darah. Bagian

ini adalah bagian dari tinjauan literatur.

Tabel 1. Ringkasan artikel

\begin{tabular}{|c|c|c|c|}
\hline No. & $\begin{array}{l}\text { Judul, Nama Penulis } \\
\text { dan Tahun Terbit }\end{array}$ & Populasi Sampel & Ringkasan Hasil \\
\hline 1. & $\begin{array}{l}\text { The Impact of Benson's } \\
\text { Relaxation Technique on } \\
\text { the Quality of Sleep in } \\
\text { the Elderly: Randomized } \\
\text { Clinical Trial Design } \\
\text { (Habibollahpour, } \\
\text { Ranjkesh, Motalebi, \& } \\
\text { Mohammadi, 2019). }\end{array}$ & 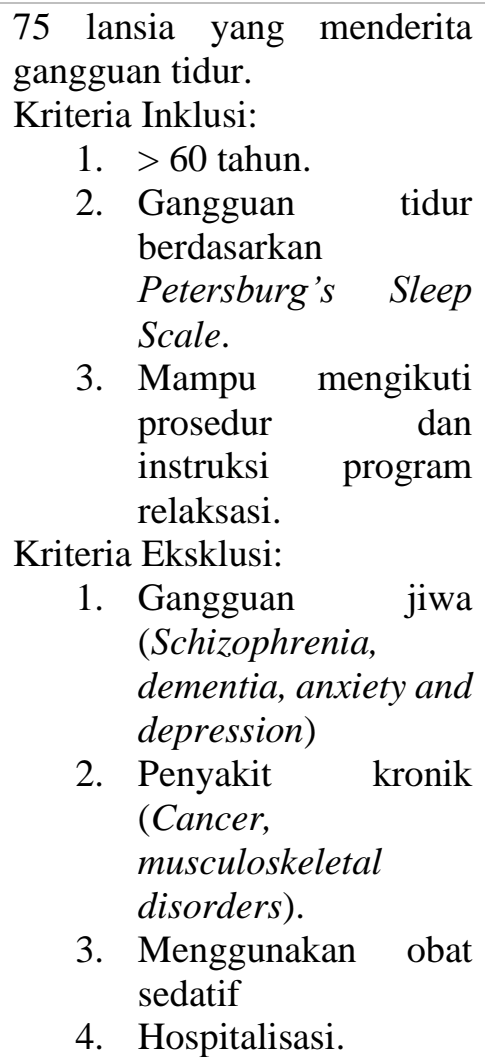 & $\begin{array}{l}\text { Hasil uji t berpasangan } \\
\text { menunjukkan peningkatan } \\
\text { yang signifikan pada } \\
\text { kelompok intervensi kualitas } \\
\text { tidur dan } 5 \text { subskala termasuk } \\
\text { kualitas tidur subjektif, } \\
\text { latensi tidur, durasi tidur, dan } \\
\text { efisiensi tidur, serta disfungsi } \\
\text { siang hari (Kurangnya } \\
\text { semangat untuk melakukan } \\
\text { aktivitas sehari - hari. } \\
\text { Meningkat secara signifikan } \\
(\mathrm{P}<0,000) \text {. }\end{array}$ \\
\hline 2. & $\begin{array}{l}\text { Efektivitas Relaksasi } \\
\text { Benson dan Nafas } \\
\text { Dalam terhadap } \\
\text { Perubahan Tingkat } \\
\text { Kecemasan Lansia di } \\
\text { Pstw Gau Mabaji Gowa: } \\
\text { Pre-Experimental } \\
\text { Design, (Sahar, Azwar, } \\
\text { Riskawati, Musdalipa, \& } \\
\text { Kasmawati 2018). }\end{array}$ & $\begin{array}{l}\text { Populasi } 95 \text { lansia. Jumlah } \\
\text { sampel } 18 \text { berusia } 60-86 \\
\text { tahun. }\end{array}$ & $\begin{array}{l}\text { Relaksasi benson dan } \\
\text { relaksasi napas dalam tidak } \\
\text { jauh berbeda, artinya sama - } \\
\text { sama efektif dalam } \\
\text { menurunkan kecemasan } \\
\text { tetapi jika dilihat dari skor } \\
\text { relaksasi lebih efektif } \\
\text { relaksasi benson menurunkan } \\
\text { kecemasan dibandingkan } \\
\text { relaksasi napas dalam. }\end{array}$ \\
\hline 3. & $\begin{array}{l}\text { Benson's relaxation } \\
\text { therapy and sleep quality } \\
\text { among elderly at a social } \\
\text { institution in inakaka, } \\
\text { Indonesia: Quasi } \\
\text { ExperimentMarasabessy } \\
\text {, Herawati, \& Achmad } \\
\text { (2020). }\end{array}$ & Populasi 46 lansia. & $\begin{array}{l}\text { Studi ini menemukan bahwa } \\
\text { terapi relaksasi benson } \\
\text { mampu meningkatkan } \\
\text { kualitas tidur lansia secara } \\
\text { signifikan }(\mathrm{p}-\text { value }=0,046) \text {, } \\
\text { dan tidak ada perbedaan yang } \\
\text { signifikan antara jenis } \\
\text { kelamin, usia dan penyakit } \\
\text { yang diderita pada kualitas } \\
\text { tidur lansia (nilai } \mathrm{p}>0,05) \text {. }\end{array}$ \\
\hline 4. & $\begin{array}{l}\text { The Modified Benson } \\
\text { Relaxation Technique To } \\
\text { Elderly Anxiety in Social } \\
\text { Home of Tresna Werdha } \\
\text { Nirwana Puri: Pre- }\end{array}$ & $\begin{array}{l}\text { Populasi } 102 \text { responden, } 16 \\
\text { sampel. }\end{array}$ & $\begin{array}{l}\text { Hasil analisis bivariat } \\
\text { menggunakan Paired t-test } \\
\text { menunjukan bahwa ada } \\
\text { pengaruh yang signifikan } \\
\text { antara tehnik relaksasi benson }\end{array}$ \\
\hline
\end{tabular}




\begin{tabular}{|c|c|c|c|}
\hline & $\begin{array}{l}\text { Experimental, } \\
\text { (Yunitasari } \\
\text { Mukhripah 2018). }\end{array}$ & & $\begin{array}{l}\text { modifikasi terhadap } \\
\text { kecemasan pada lansia yaitu } p \\
\text { value } 0.000<0.05 \text {. }\end{array}$ \\
\hline 5. & $\begin{array}{l}\text { The Effect of Benson's } \\
\text { Relaxation Technique on } \\
\text { Anxiety, Depression and } \\
\text { Sleep Quality of Elderly } \\
\text { Patients Undergoing } \\
\text { Hemodialysis: Quasi- } \\
\text { Eksperimental,(Eman } \\
\text { Baleegh Meawad } \\
\text { Elsayed, Eman Hassan, } \\
\text { 2019). }\end{array}$ & $\begin{array}{l}\text { Sampel dari } 92 \text { pasien lanjut } \\
\text { usia yang dijadwalkan untuk } \\
\text { hemodialisis. }\end{array}$ & $\begin{array}{l}\text { Semua skor total rata - rata } \\
\text { hospital anxiety scale, } \\
\text { depression scale, and } \\
\text { pittsburgh sleep quality index } \\
\text { untuk pasien lanjut usia } \\
\text { meningkat secara signifikan } \\
\text { setelah menerapkan teknik } \\
\text { relaksasi benson. }\end{array}$ \\
\hline 6. & $\begin{array}{lr}\text { Pengaruh } & \text { Teknik } \\
\text { Relaksasi } & \text { Benson } \\
\text { Terhadap Kualitas Tidur } \\
\text { pada Lanjut Usia: Quasi- } \\
\text { Experimental, (Rahmat } \\
\text { Hidayat \&Haeril Amir } \\
\text { 2021). }\end{array}$ & $\begin{array}{l}\text { Populasi } 100 \text { lansia, sampel } \\
20 .\end{array}$ & $\begin{array}{l}\text { Terdapat perbedaan yang } \\
\text { signifikan rata-rata kualitas } \\
\text { tidur klien lansia antara } \\
\text { kelompok intervensi sebelum } \\
\text { dan setelah dilakukan } \\
\text { relaksasi benson }(\mathrm{p}=0,000) \text {. }\end{array}$ \\
\hline 7. & $\begin{array}{lr}\text { Pengaruh } & \text { Terapi } \\
\text { Relaksasi } & \text { Benson } \\
\text { Terhadap } & \text { Tekanan } \\
\text { Darah: Desain } & \text { Quasy- } \\
\text { Experimental, } \\
\text { (Febriyanti, Viki Yusri, } \\
\text { Nova Fridalni, 2021). }\end{array}$ & $\begin{array}{l}\text { Populasi } 418 \text { orang. Sampel } \\
15 \text { orang penderita hipertensi. }\end{array}$ & $\begin{array}{l}\text { Terdapat perbedaan yang } \\
\text { signifikan antara tekanan } \\
\text { darah sistole pada lansia } \\
\text { dengan hipertensi sesudah } \\
\text { dilakukan terapi relaksasi } \\
\text { benson dengan nilai } \mathrm{p}=0,009 \text {. }\end{array}$ \\
\hline 8. & $\begin{array}{lr}\text { Pengaruh } & \text { Terapi } \\
\text { Relaksasi } & \text { Benson } \\
\text { Terhadap Kadar Gula } \\
\text { Darah Pada Lansia } \\
\text { Dengan } & \text { Diabetes: } \\
\text { Desain } & \text { Quasy- } \\
\text { Experiment, } & \text { (Juwita, } \\
\text { Prabasari, } & \& \\
\text { Manungkalit, 2016). }\end{array}$ & $\begin{array}{l}\text { Populasi: semua lansia } \\
\text { penderita DM di Posyandu } \\
\text { Lansia Matahari Surabaya. } \\
\text { Sampel: } 38 \text { responden. }\end{array}$ & $\begin{array}{l}\text { Hasil penelitian } \\
\text { kontrol yaitu p }=0,0005 \\
\text { sedangkan } \\
\text { perlakuan p } \quad \text { kelompok } \\
\text { sehingga relaksasi benson } \\
\text { dapat menurunkan kadar gula } \\
\text { darah pada lansia dengan } \\
\text { DM. }\end{array}$ \\
\hline 9. & $\begin{array}{lr}\text { Penurunan } & \text { Stress Pada } \\
\text { Lansia } & \text { Dengan } \\
\text { Relaksasi } & \text { Benson: } \\
\text { Quasy-Experimental, } \\
\text { (Abdul Rokhman, 2021). }\end{array}$ & $\begin{array}{lrl}\text { Sampel: } & \text { lansia } & \text { yang } \\
\text { berjumlah } 30 & \text { lansia. } & \end{array}$ & $\begin{array}{l}\text { Hasil penelitian diperoleh } \\
\text { nilai median skor stress lansia } \\
\text { sebelum melakukan relaksasi } \\
\text { benson yaitu } 20 \text {, dan setelah } \\
\text { lansia melakukan relaksasi } \\
\text { benson nilai median skor } \\
\text { stress lansia mengalami } \\
\text { penurunan menjadi } 16 \text { dengan } \\
\text { nilai }(p=0,000) \text {. }\end{array}$ \\
\hline 10. & $\begin{array}{l}\text { Effectiveness of Benson } \\
\text { Relaxation on Reduction } \\
\text { of Blood: Desain Quasy- } \\
\text { Experimental. } \\
\text { (Juwariyah, } \\
\text { Suciwati, 2018). Siti }\end{array}$ & $\begin{array}{l}\text { Populasi: } 50 \text { lansia laki - laki } \\
\text { dan Wanita dengan hipertensi } \\
\text { usia } 60 \text { - } 87 \text { tahun. Sampel } 25 \\
\text { responden. }\end{array}$ & $\begin{array}{l}\text { Hasil penelitian menunjukan } \\
\text { bahwa ada efek relaksasi } \\
\text { benson terhadap penurunan } \\
\text { tekanan darah tinggi lansia } \\
\text { dengan hipertensi dengan } \\
\text { nilai P signifikan <0,05 dari } \\
0,00 \text { kesimpulan: lansia } \\
\text { dianjurkan menerapkan } \\
\text { relaksasi benson untuk }\end{array}$ \\
\hline
\end{tabular}




\section{SIMPULAN}

Terapi relaksasi benson merupakan terapi yang mudah dilakukan oleh para lansia dimana saja dan kapan saja serta tidak memerlukan biaya, pelaksanaan terapi ini menggabungkan terapi relaksasi nafas dalam dengan faktor keyakinan seperti berdzikir. Berdasarkan 10 artikel yang ditemukan dalam pencarian dari Google Scholar, Science Direct dan Pubmed, disimpulkan bahwa terapi relaksasi benson efektif untuk menurunkan kesulitan tidur, kecemasan, stress, tekanan darah, gula darah pada lansia, dan mengatasi cemas, depresi, serta kualitas tidur pada pasien lansia dengan hemodialisa. Sedangkan untuk waktu relaksasi benson ini efektif dilakukan selama 10-30 menit dalam sehari. Bagi peneliti selanjutnya, hasil penelitian ini dapat digunakan sebagai bahan referensi untuk memperdalam penelitian berikutnya, seperti mencari sumber yang lebih banyak, akurat dan spesifik. Ilmu tersebut mampu diupgrade khususnya terapi benson yang merupakan terapi nonfarmakologi sehingga dapat membantu guna mengatasi banyak permasalahan lansia.

\section{UCAPAN TERIMA KASIH}

Penulis mengucapkan terimakasih kepada seluruh dosen STIKes Mitra Keluarga yang telah berpartisipasi untuk waktu dan masukkan yang telah diberikan dalam penyusunan artikel ini.

\section{KONFLIK KEPENTINGAN}

Penulis tidak memiliki konflik dengan pihak manapun selama penyusunan artikel.

\section{REFERENSI}

1. BPHN. Undang-Undang No 13 Tahun 1998 Tentang Kesejahteraan Lanjut Usia. Jakarta: Hukum Administrasi Negara; 1998.

2. Kementerian Kesehatan RI. Situasi lanjut usia (lansia). Infodatin; 2016.

3. Sunaryo, Rahayu W, Maisje M, Taat S, Esti D, Ulfah A, et al. Asuhan Keperawatan Gerontik. Christian P, editor. Yogyakarta: CV Andi Offset; 2015.

4. Sunaryo, Rahayu. Asuhan Keperawatan Gerontik - Google Books. 1st ed. Yogyakarta: CV. ANDO OFFSET; 2015.

5. Gunardi S, Herlina I. Insomnia Dapat Meningkatkan Resiko Depresi Lansia. J Heal Sciece. 2021;I(01):34-42.

6. Badan Penelitian dan Pengembangan Kesehatan. Riset Kesehatan Dasar. Jakarta; 2013.

7. Tetti, Solehati \& Cecep EK. Konsep \& aplikasi relaksasi dalam keperawatan maternitas. 2015.

8. Pradana AA, Sahar J, Permatasari H. Integration of Therapy in Reducing the Onset of Depression in Older Adults: Case Report. KnE Life Sci. 2021;2021(3):115-23.

9. Benson $\mathrm{H}$, Proctor W. Relaxation Revolution The Science and Genetics of Mind Body Healing. Scribner; 2011.

10. Abdullah Ibrahim, Gonul Koyuncu, Nazmiye Koyuncu, Neslihan Ergun Suzer, Oya Durmus Cakir OK. The effect of Benson relaxation method on anxietyin the emergency care. Medicine (Baltimore). 2019; 
11. Habibollahpour M, Ranjkesh F, Motalebi SA, Mohammadi F. The Impact of Benson's Relaxation Technique on the Quality of Sleep in the Elderly. Top Geriatr Rehabil. 2019;35(1):88-94.

12. Sahar RH, Azwar, Riskawati, Musdalipa, Kasmawati. Efektivitas Relaksasi Benson dan Nafas Dalam terhadap Perubahan Tingkat Kecemasan Lansia di PSTW GAU MABAJI GOWA. BIMIKI. 2018;6(1):20-33.

13. Marasabessy NB, Herawati L, Achmad I. Benson's relaxation therapy and sleep quality among elderly at a social institution in inakaka, Indonesia. Kesmas. 2020;15(2):65-72.

14. Yunitasari E, Mukhripah D. The Modified Benson Relaxation Technique To Elderly Anxiety in Social Home of Tresna Werdha Nirwana Puri. Publ Manuscr Modif Benson Relax Tech To Elder Anxiety Soc Home Tresna Werdha Nirwana Puri. 2018;1-14.

15. Meawad Elsayed EB. The Effect of Benson's Relaxation Technique on
Anxiety, Depression and Sleep Quality of Elderly Patients Undergoing Hemodialysis. Int $\mathbf{J}$ Nurs Didact. 2019;09(02):23-31.

16. Hidayat R, Amir H. Pengaruh Teknik Relaksasi Benson Terhadap Kualitas Tidur pada Lanjut Usia. An Idea Heal J. 2021;1(1):21-5.

17. Yusri V, Fridalni N, Lubuk K, Rw L, Padang KK, Kunci K. Pengaruh Terapi Relaksasi Benson Terhadap Tekanan Darah. Menara Ilmu. 2021;XV(01):51-7.

18. Juwita L, Prabasari NA, Manungkalit M. Pengaruh Terapi Relaksasi Benson Terhadap Kadar Gula Darah Pada Lansia Dengan Diabetes. J Ners LENTERA. 2016;4(1):9.

19. Rokhman A. Penurunan Stress Pada Lansia Dengan Relaksasi Benson. J Ilm Kesehat Media Husada. 2021;10(1):52-8.

20. Juwariyah SS. Effectiveness of Benson Relaxation on Reduction of Blood. J Ilmu Keperawatan dan Kebidanan STIKES Telogorejo Semarang. 2018;10(1):1-6. 